\title{
Oxygen-18 isotopes in precipitation on the eastern Tibetan Plateau
}

\author{
YU Wusheng, ${ }^{1,2}$ YAO Tandong, ${ }^{1}$ TIAN Lide, ${ }^{1}$ WANG Yu, ${ }^{2}$ LI Zexia, ${ }^{2}$ SUN Weizhen ${ }^{2}$ \\ ${ }^{1}$ Laboratory of Environment and Process on Tibetan Plateau, Institute of Tibetan Plateau Research, \\ Chinese Academy of Sciences, Beijing 100085, China \\ E-mail: yuws@itpcas.ac.cn \\ ${ }^{2}$ Laboratory of Cryosphere and Environment, Cold and Arid Regions Environmental and Engineering Research Institute, \\ Chinese Academy of Sciences, Lanzhou 730000, China
}

\begin{abstract}
This study examines precipitation samples collected at the Yushu meteorological station on the eastern Tibetan Plateau from November 2000 to November 2002. Results show that air-temperature effects control $\delta^{18} \mathrm{O}$ in precipitation in this area. Values of $\delta^{18} \mathrm{O}$ in precipitation positively correlate with air temperature, especially for monthly averages. Our data also show $\delta^{18} \mathrm{O}$ values in precipitation positively correlate with dew point and surface pressure in the Yushu region. Similar to other stations (Tuotuohe, Nagqu, Gaize and Shiquanhe) lying in the transition zone between the regions in the south dominated by the monsoon and those in the north dominated by the westerlies, because of the effect of monsoon precipitation, precipitation rates are high, and heavy isotopes are more depleted in summer at the Yushu station. Accordingly, values of $\delta^{18} \mathrm{O}$ in precipitation correlate more strongly with air temperature and dew point before the monsoon onset and after the monsoon retreat than during the monsoon period. That is, intense monsoon activities weaken the correlations between $\delta^{18} \mathrm{O}$ and air temperature and dew point. Clearly, dew point, surface pressure and the monsoon intensity contribute to controlling the $\delta^{18} \mathrm{O}$ values in precipitation at the Yushu station.
\end{abstract}

\section{INTRODUCTION}

Many researchers have used stable isotopes as a tool for reconstructing paleoclimate variations represented in icecore records (e.g. Cuffey and others, 1994; Johnsen and others, 1995). However, the interpretation of stable-isotope records in ice cores must be based on knowledge of the variations of stable isotopes in precipitation with meteorological conditions (Dansgaard, 1964; Merlivat and Jouzel, 1979; Jouzel and Merlivat, 1984; Rozanski and others, 1992). The International Atomic Energy Agency (IAEA), in cooperation with the World Meteorological Organization (WMO), set up 550 meteorological stations that have measured the isotopic composition of monthly precipitation since 1961. However, in some regions, such as on the Tibetan Plateau (TP), few stations belong to the IAEA/WMO global network for monitoring isotopes in precipitation. IAEA/WMO set up one station at Lhasa on the TP in 1986, but this operated for only 7 years and was of insufficient duration or scope to study the isotopic composition of precipitation over such an extensive region as the TP. In 1991, the Chinese Academy of Sciences launched a program to establish a new observation network to continually survey isotopic compositions on the TP and adjacent regions. Due to the TP's unique geographic position and topography, its moisture origins are complex. The different moisture sources interact to affect the spatial and temporal variations of stable isotopes in precipitation. Stable isotopes in precipitation show an apparent precipitation 'amount effect' in the south of the TP, related to the effect of monsoon activities (Araguás-Araguás and others, 1998; Tian and others, 2001b, c, 2003). On the northern TP, beyond the extent of the monsoon precipitation, temperature effects control $\delta^{18} \mathrm{O}$ in precipitation (Zhang and others, 1995; Yao and others, 1996, 1999; Tian and others, 2001b, 2003).

To observe $\delta^{18} \mathrm{O}$ in precipitation over a more extensive region on the TP, we established the Yushu station in the east, and the Gaize and Shiquanhe stations in the west of the TP. Based on precipitation sampling at Yushu, this paper presents the relationship between $\delta^{18} \mathrm{O}$ in precipitation and meteorological conditions, and discusses the variation of $\delta^{18} \mathrm{O}$ with the effect of moisture transport in this region. In addition, we compare the $\delta^{18} \mathrm{O}$ variation at Yushu with that at the Gaize and Shiquanhe stations, on the western TP, and at the Tuotuohe and Nagqu stations, in the central part of the TP. These stations all lie within a narrow band of latitude.

\section{METHODS AND MATERIALS}

\section{Study area}

Yushu lies in the eastern part of the TP, between the Bayan Har Shan and the Tanggula Shan, with an average altitude of $4500 \mathrm{~m}$. The sources of the Yangtze, Yellow and Lantsang rivers are traced to basins at the foot of these mountains (Fig. 1). This region has an annual average temperature of $-8^{\circ} \mathrm{C}$ and an average annual rainfall of $464 \mathrm{~mm}$.

\section{Precipitation sampling and measurement}

The Yushu meteorological station $\left(33^{\circ} 01^{\prime} \mathrm{N}, 97^{\circ} 01^{\prime} \mathrm{E}\right.$; $3682 \mathrm{ma.s.l}$.) launched a program to monitor oxygen isotopes in precipitation in November 2000 (data analyzed come from the sampling period November 2000-November 2002). We sampled each precipitation event, and 216 samples were collected. Rainfall samples were collected and immediately sealed in plastic bottles. Snow and other solid precipitation was collected on clean porcelain plates, put into clean plastic bags and sealed. After the samples melted at room temperature, they were processed the same as rainfall. All the samples were stored below freezing in a cold laboratory until analyzed. The Key Laboratory of Cryosphere and Environment, Lanzhou, measured oxygen isotope compositions of all the precipitation samples using a MAT252 mass spectrometer with a precision of $0.2 \%$. The 


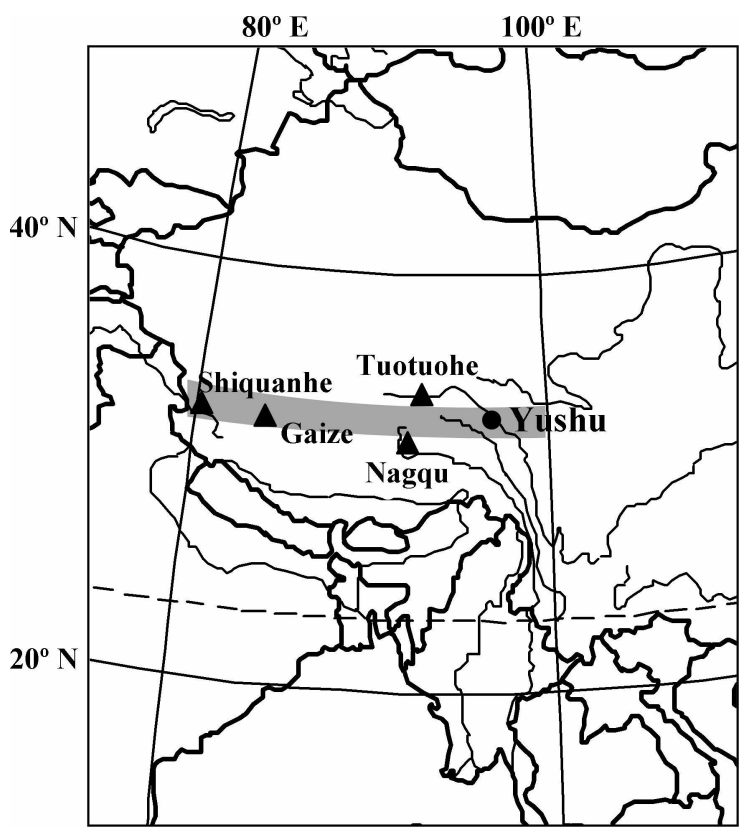

Fig. 1. Map of the precipitation sampling sites at Yushu on the eastern TP, and adjacent regions. The shadowed region is a transition zone between the regions in the south dominated by the monsoon and the regions in the north dominated by the westerlies.

measured ratio of the stable oxygen isotopes in precipitation samples is expressed as parts per mil of their deviation relative to the Vienna Standard Mean Ocean Water (VSMOW).

\section{Meteorological data}

The precipitation-sampling program recorded the duration of each precipitation event, the rainfall amount, wind direction and wind speed (before and after each precipitation event). Other relevant meteorological data, such as dew point and surface pressure, were obtained from the National Meteorological Information Center of China. In addition, we used re-analysis datasets from the US National Centers for Environmental Prediction (NCEP) and the US National Center for Atmospheric Research (NCAR) to calculate the wind field and humidity field for $500 \mathrm{hPa}$ over the TP and adjacent regions, to determine the origin of moisture and to analyze the effect of moisture transport upon $\delta^{18} \mathrm{O}$ of precipitation in this region. The NCEP/NCAR datasets include monthly-averaged wind direction, monthlyaveraged wind speed and monthly-averaged relative humidity re-analysis data, with a spatial precision of $2.5^{\circ}$ longitude-latitude grids (available at http://www.cdc.noaa.gov/ cgi-bin/db_search/SearchMenus.pl).

\section{RESULTS}

Figure 2 shows the relationship between $\delta^{18} \mathrm{O}$ in precipitation and air temperature in recent precipitation events at the Yushu meteorological station. The $\delta^{18} \mathrm{O}$ values in precipitation and temperature $(T)$ in this area correlate with a regression that can be expressed as: $\delta^{18} \mathrm{O}=0.17 T-12.48$ $(r=0.20)$. The correlation coefficient is 0.20 , within a 0.01 confidence limit.

Figure 3 compares the variation of monthly-averaged $\delta^{18} \mathrm{O}$ and monthly-averaged temperature at the Yushu

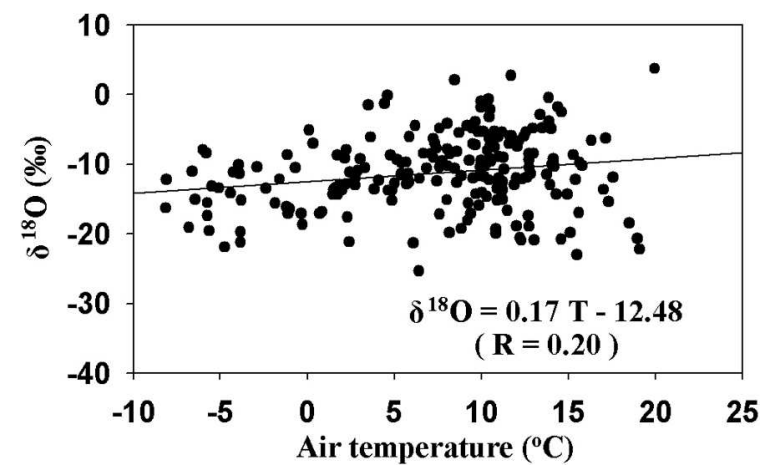

Fig. 2. Relationship between $\delta^{18} \mathrm{O}$ and air temperature in recent precipitation events at the Yushu station.

station. We find a better correlation between monthlyaveraged $\delta^{18} \mathrm{O}$ and monthly-averaged temperature than that for individual precipitation events (above). Results from a linear regression least-squares fit using monthly-averaged data can be expressed as follows:

$$
\delta^{18} \mathrm{O}=0.29 \bar{T}-13.60 \quad(r=0.61) .
$$

Clearly, monthly averages of $\delta^{18} \mathrm{O}$ in precipitation and air temperature on the eastern TP produce the best least-squares fit and a better $\delta^{18} \mathrm{O}-T$ correlation. This shows a temperature effect on $\delta^{18} \mathrm{O}$ in precipitation in the period of sampling from the seasonal variation in this region.

The variations of the $\delta^{18} \mathrm{O}$ values of precipitation correlate not only with temperature, but also with dew point and surface pressure. The relationship between $\delta^{18} \mathrm{O}$ in precipitation and dew point $\left(T_{\mathrm{DP}}\right)$ in recent precipitation events at Yushu is

$$
\delta^{18} \mathrm{O}=0.09 T_{\mathrm{DP}}-11.43 \quad(r=0.12) .
$$

Although the correlation coefficient is very small $(r=0.12)$, there is a positive correlation trend between $\delta^{18} \mathrm{O}$ in precipitation and dew point. Compared with the relationship for individual precipitation events, the correlation between monthly-averaged $\delta^{18} \mathrm{O}$ and monthly-averaged dew point is better. The correlation coefficient is 0.61 , within a 0.01 confidence limit:

$$
\delta^{18} \mathrm{O}=0.026 \bar{T}_{\mathrm{DP}}-11.64 \quad(r=0.61) .
$$

There is a positive correlation between $\delta^{18} \mathrm{O}$ in precipitation and surface pressure $(P)$ at Yushu:

$$
\delta^{18} \mathrm{O}=0.32 P-220.3 \quad(r=0.20) .
$$

Moreover, there is a stronger correlation using monthlyaveraged surface pressures, with a correlation coefficient of 0.45 :

$$
\delta^{18} \mathrm{O}=0.46 \bar{P}-311.7 \quad(r=0.45) .
$$

At the same time, we calculated the correlations of the precipitation-weighted monthly means of $\delta^{18} \mathrm{O}$ with air temperature, dew point and surface pressure, and found all the correlations of weighted means of $\delta^{18} \mathrm{O}$ and meteorological factors were poorer than those of monthly-averaged $\delta^{18} \mathrm{O}$ and meteorological factors (equations omitted). The results may be attributed to undue weight assigned to correlation coefficients with regard to the Yushu data. In brief, the variation of $\delta^{18} \mathrm{O}$ in precipitation at the Yushu station is closely related to the variations of air temperature, 


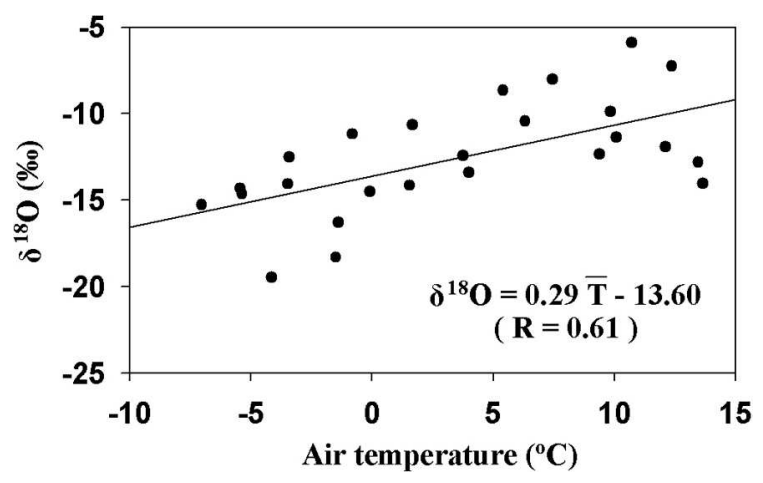

Fig. 3. The variations of monthly-averaged $\delta^{18} \mathrm{O}$ and monthlyaveraged air temperature at the Yushu station.

dew point and surface pressure, especially for the monthly averages. That is, air temperature, dew point and surface pressure are the main environmental variables correlated with $\delta^{18} \mathrm{O}$ in precipitation at the Yushu station. Accordingly, we attempt to deal with these data (monthly-averaged) for multiple regression analysis. Multiple regression analysis is a convenient method for viewing stable isotopes in precipitation in more than two dimensions, treating $\delta^{18} \mathrm{O}$ (Johnson and Ingram, 2004). We model $\delta^{18} \mathrm{O}$ as a function of air temperature, dew point and surface pressure by using a simple multiple regression model:

$$
\delta^{18} \mathrm{O}=\beta_{0}+\beta_{T} T+\beta_{\mathrm{DP}} \mathrm{DP}+\beta_{P} P .
$$

In this study, we used the SPSS default method, Enter, which is a standard approach in regression models. Based on the output of this model, the standardized coefficients, or beta coefficients, are $0.188,0.363$ and 0.109 for the airtemperature, dew-point and surface-pressure variables, respectively. Hence, Equation (6) can be expressed as:

$$
\delta^{18} \mathrm{O}=-85.4+0.19 T+0.36 \mathrm{DP}+0.11 P \quad(R=0.62) .
$$

The value of the multiple correlation coefficient $(R)$ between all of the independent variables (air temperature, dew point and surface pressure) and the dependent variable $\left(\delta^{18} \mathrm{O}\right)$ is 0.62 . The $F$ statistic is significant at less than the $5 \%$ level. Furthermore, the beta coefficient for dew point is higher than those for air temperature and surface pressure. Accordingly, the $\delta^{18} \mathrm{O}$ values of precipitation correlate more closely to dew point than to air temperature and surface pressure.

\section{DISCUSSION}

In recent years, results of some studies confirmed that the region $32-33^{\circ} \mathrm{N}$ (the Tanggula Shan range, extending from west to east) forms an important climatic divide. These massive mountains block the flow of the southwest monsoon from the south. As a result, the monsoon prevails in the south of the Tanggula Shan, whereas the north is chiefly influenced by the continental air mass (Yao, 1991; Tian and others, 1995). Hence, the temperature effect controls $\delta^{18} \mathrm{O}$ in precipitation in the north, whereas there is an 'amount effect' for the $\delta^{18} \mathrm{O}$ values related to the monsoon precipitation in the south. The Yushu station lies within this climatic divide, at the foot of the northeast Tanggula Shan. Hence, Yushu sits in a transition zone between the regions in the
Table 1. Correlations between $\delta^{18} \mathrm{O}$ in precipitation and air temperature at the Yushu, Tuotuohe, Nagqu, Gaize and Shiquanhe stations. $n$ is the number of precipitation samples

\begin{tabular}{llrrr}
\hline Station & Period & $\mathrm{d} \delta^{18} \mathrm{O} / \mathrm{d} T$ & $R$ & \multicolumn{1}{c}{$n$} \\
\hline Yushu & November 2000-November 2002 & 0.29 & 0.61 & 216 \\
Tuotuohe & January 2000-September 2002 & 0.28 & 0.45 & 240 \\
Nagqu & January 2000-November 2002 & -0.17 & -0.25 & 569 \\
Gaize & July 1998-September 2002 & 0.33 & 0.53 & 196 \\
Shiquanhe & February 1999-August 2002 & 0.57 & 0.70 & 63 \\
\end{tabular}

* Relationship calculated for the entire year; there is no positive correlation between $\delta^{18} \mathrm{O}$ in precipitation and air temperature.

†Sample collection in 2000 was incomplete at the Shiquanhe station.

south dominated by the monsoon and those in the north dominated by the westerlies. In this zone, the westerlies and monsoon intermingle, with the monsoon dominating in summer. The rest of the year, the westerlies mainly control the moisture origins at Yushu. Consequently, $\delta^{18} \mathrm{O}$ in precipitation shows temperature dependence at the annual scale. The monsoon activities in summer weaken the correlation between $\delta^{18} \mathrm{O}$ and air temperature. Other stations lying in the climatic divide include Tuotuohe $\left(34^{\circ} 13^{\prime} \mathrm{N}, 92^{\circ} 26^{\prime} \mathrm{E} ; 4533 \mathrm{~m}\right.$ a.s.I.) and Nagqu $\left(31^{\circ} 29^{\prime} \mathrm{N}\right.$, $92^{\circ} 04^{\prime} \mathrm{E} ; 4508 \mathrm{ma.s.I}$.) on the central TP, and Gaize $\left(32^{\circ} 18^{\prime} \mathrm{N}, 84^{\circ} 04^{\prime} \mathrm{E} ; 4430 \mathrm{ma.s.l}\right.$. $)$ and Shiquanhe $\left(32^{\circ} 30^{\prime} \mathrm{N}, 80^{\circ} 05^{\prime} \mathrm{E} ; 4278 \mathrm{ma.s.l}\right.$. $)$ in the west. All these stations lie in the transition belt between 'temperature effect' regions in the north and 'amount effect' regions in the south, and the variation patterns of $\delta^{18} \mathrm{O}$ in precipitation at all these stations are similar. Except for Nagqu, $\delta^{18} \mathrm{O}$ variations in precipitation relate closely to the variations of temperature on a scale of years (see Table 1), and the $\delta^{18} \mathrm{O}$ values are low in summer, due to the monsoon precipitation (Tian and others, 2003; Yu and others, 2004). The closer proximity to the monsoon region results in the variations of $\delta^{18} \mathrm{O}$ in precipitation at Nagqu being more similar to the $\delta^{18} \mathrm{O}$ variations in the south of the TP (Tian and others, 2001a, 2003). However, before the monsoon onset, air temperature remains the dominant factor that controls the variations of $\delta^{18} \mathrm{O}$ in this area ( $\mathrm{Yu}$ and others, unpublished information; see Table 2). Table 2 also shows that the correlations of $\delta^{18} \mathrm{O}$ and air temperature before the monsoon onset are more significant than those on a scale of years at these stations; furthermore, the slopes $\left(\mathrm{d} \delta^{18} \mathrm{O} / \mathrm{d} T\right)$ are higher than those for the entire year. Clearly, the monsoon activities in summer affect the relationships between $\delta^{18} \mathrm{O}$ in precipitation and air temperature in the transition zone.

Figure 4 shows the seasonal variation of $\delta^{18} \mathrm{O}$ in precipitation with air temperature, dew point and surface pressure at the Yushu station. The bar graph at the bottom of the figure shows daily rainfall. Note that air-temperature (Fig. 4a) and dew-point (Fig. 4b) trends follow similar tendencies, with high values in summer and low values in winter. Although the details of the curve of surface pressure are complex, there also exists a trend of high values in summer and low values in winter (Fig. 4c).

The comparison of surface-pressure and $\delta^{18} \mathrm{O}$ variations in precipitation is more complex (Fig. 4d). From November 2000 to early May 2001, before the southwest monsoon onset, the $\delta^{18} \mathrm{O}$ values increased gradually, consistent with 


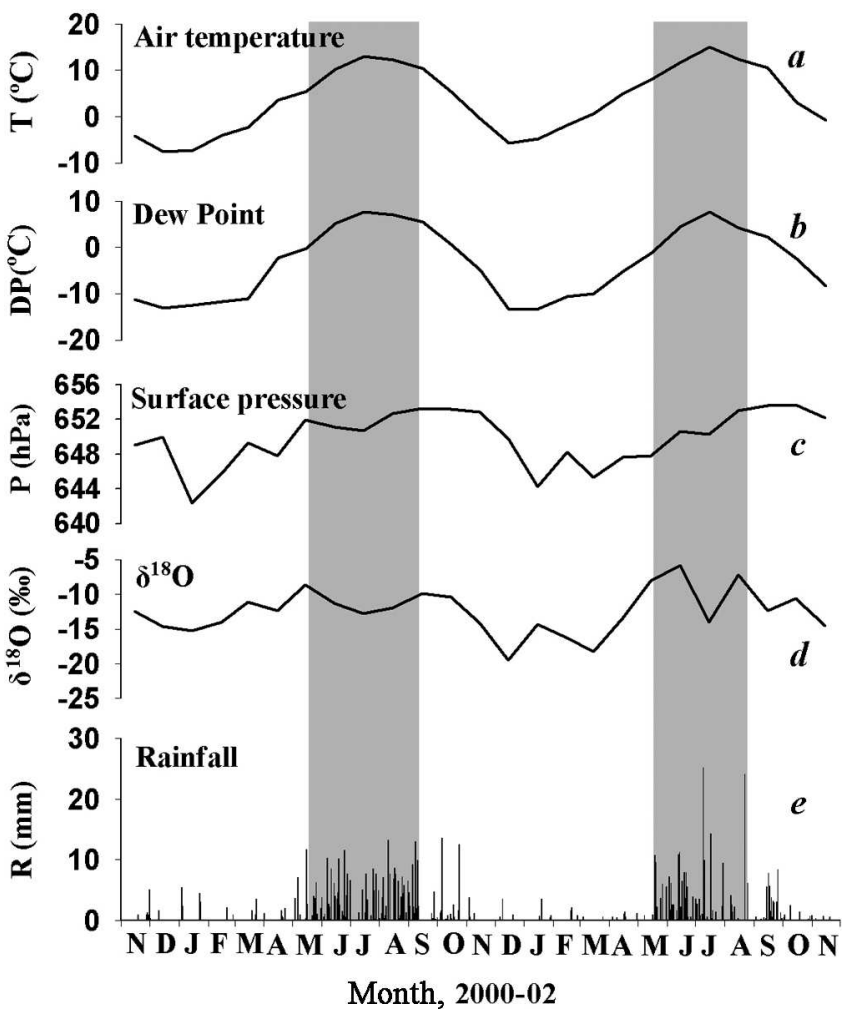

Fig. 4. Seasonal changes in air temperature (a), dew point (b), surface pressure (c) and $\delta^{18} \mathrm{O}$ in precipitation (d) at the Yushu station. Bar graph shows daily rainfall (e).

the air-temperature, dew-point and surface-pressure trends. Apparently, temperature effects control $\delta^{18} \mathrm{O}$ in precipitation in this area, but dew point and surface pressure also cause variations in $\delta^{18} \mathrm{O}$. Some of the trends of surface pressure and $\delta^{18} \mathrm{O}$ in precipitation are synchronous: both surface pressure and $\delta^{18} \mathrm{O}$ values increased gradually in February, then decreased in March and increased again in April. Before the monsoon onset, the moisture origins are controlled by the westerlies, the frequency of precipitation events is very low and the rainfall of each precipitation event is very small (Fig. 4e).

During the rainy season between late May and August 2001, the monsoon activities were very strong at Yushu, and $\delta^{18} \mathrm{O}$ values were low (they reach a minimum at the end of July or in early August), while summer air temperatures and dew points remained high. After the monsoon onset, however, the surface pressure decreased gradually, coincident with the $\delta^{18} \mathrm{O}$ values. Apparently, the monsoon precipitation has less effect on the $\delta^{18} \mathrm{O}-P$ than on the $\delta^{18} \mathrm{O}-$ $T$ and $\delta^{18} \mathrm{O}-T_{\mathrm{DP}}$ correlations. The southwest monsoon activities in summer cause the frequency of precipitation events to increase rapidly, and rainfall amounts also increase during the monsoon (Fig. 4e).

With the attenuation of monsoon precipitation, the $\delta^{18} \mathrm{O}$ values increased gradually for a short time in early September 2001. After October 2001, because of the complete monsoon retreat, the temperature remained the dominant factor controlling the variation of $\delta^{18} \mathrm{O}$. With air temperature descending gradually, the $\delta^{18} \mathrm{O}$ values decreased correspondingly, reaching a minimum in early December 2001, when air temperature was also at a low point in its curve. After the monsoon retreat, the westerlies mainly control the moisture origins in the area, and the
Table 2. Relationships between $\delta^{18} \mathrm{O}$ in precipitation and air temperature before monsoon activities at five stations

\begin{tabular}{llllr}
\hline Station & Period & $\mathrm{d} \delta^{18} \mathrm{O} / \mathrm{d} T$ & $R$ & $n$ \\
\hline Yushu & January-May & 0.47 & 0.70 & 46 \\
Tuotuohe & January-May & 0.78 & 0.73 & 44 \\
Nagqu & January-May & 0.57 & 0.51 & 128 \\
Gaize & January-June* & 0.74 & 0.75 & 25 \\
Shiquanhe & January-June* & 0.77 & 0.72 & 21 \\
& & & & \\
\hline
\end{tabular}

*The rainy season starts around July at the Gaize and Shiquanhe stations.

content of atmospheric water vapor decreased immediately, resulting in sparse precipitation in this region. Similar to air temperature, dew point and surface pressure also descended gradually, contributing to the lowering of $\delta^{18} \mathrm{O}$ in precipitation.

In 2002, seasonal variations of $\delta^{18} \mathrm{O}$ with air temperature, dew point and surface pressure were very similar to those in 2001 (Fig. 4). Before the monsoon onset and after the monsoon retreat, the positive correlations between $\delta^{18} \mathrm{O}$ in precipitation and air temperature, dew point and surface pressure are all significant, and $\delta^{18} \mathrm{O}$ in precipitation shows very strong temperature dependence. During the monsoon precipitation, however, the $\delta^{18} \mathrm{O}$ values in precipitation were low, and they correlate much more poorly with air temperature, dew point and surface pressure. This relates to the moisture being transported from the Indian Ocean into the Yushu region. Similarly, before the monsoon onset and after the monsoon retreat, the moisture origins are controlled by the westerlies, resulting in reduced rainfall at the Yushu station in 2002. About $80 \%$ of the annual rainfall occurred during the monsoon, as documented in Figure $4 \mathrm{e}$.

Table 3 lists the correlation coefficients and slopes $\left(\mathrm{d} \delta^{18} \mathrm{O} / \mathrm{d} T\right)$ in the equations of $\delta^{18} \mathrm{O}$ in precipitation with air temperature, dew point and surface pressure, before monsoon activities (January-May), during the rainy season (June-August), after monsoon retreat (September-December) and in the whole precipitation sampling period (January-December) for both years at the Yushu station. Before the monsoon onset and after the monsoon retreat, the $\delta^{18} \mathrm{O}-T$ and $\delta^{18} \mathrm{O}-T_{\mathrm{DP}}$ correlations are more significant than those for the whole sampling period, and the slopes $\left(\mathrm{d} \delta^{18} \mathrm{O} / \mathrm{dT}\right)$ are also higher than those for the full year. However, during the rainy season, the values of the correlation coefficients and slopes in the equations of $\delta^{18} \mathrm{O}$ and air temperature and dew point are negative (see Table 3). That is, the monsoon precipitation in summer weakens the correlations between $\delta^{18} \mathrm{O}$ and air temperature and dew point in this region. Compared with air temperature and dew point, the correlation with surface pressure in the whole precipitation sampling period $(R=0.20)$ appears similar in the period before the monsoon onset $(R=0.29)$ to that after the monsoon retreat $(R=0.36)$, even though during the rainy season the correlation coefficient and slope values in the equations of $\delta^{18} \mathrm{O}$ and surface pressure are positive (see Table 3). We conclude that the southwest monsoon activities have less effect upon the correlation between $\delta^{18} \mathrm{O}$ and surface pressure than upon the correlations between $\delta^{18} \mathrm{O}$ and temperature and dew point. As previously shown (Fig. 4c and d), during the monsoon 
Table 3. Relationships between $\delta^{18} \mathrm{O}$ in precipitation and air temperature, dew point and surface pressure before monsoon activities (January-May), during the rainy season (June-August), after monsoon retreat (September-December) and in the whole precipitation sampling period (January-December). $n$ is the number of precipitation samples

\begin{tabular}{|c|c|c|c|c|}
\hline & Period & Slope & $R$ & $n$ \\
\hline \multirow[t]{4}{*}{$\delta^{18} \mathrm{O}-T$} & January-May & 0.51 & 0.59 & 46 \\
\hline & June-August & -0.08 & -0.04 & 127 \\
\hline & September-December & 0.38 & 0.39 & 43 \\
\hline & January-December & 0.17 & 0.2 & 216 \\
\hline \multirow[t]{4}{*}{$\delta^{18} \mathrm{O}-\mathrm{DP}$} & January-May & 0.28 & 0.6 & 46 \\
\hline & June-August & -0.68 & -0.32 & 127 \\
\hline & September-December & 0.27 & 0.34 & 43 \\
\hline & January-December & 0.09 & 0.12 & 216 \\
\hline \multirow[t]{4}{*}{$\delta^{18} \mathrm{O}-P$} & January-May & 0.37 & 0.29 & 46 \\
\hline & June-August & 0.37 & 0.15 & 127 \\
\hline & September-December & 0.61 & 0.36 & 43 \\
\hline & January-December & 0.32 & 0.2 & 216 \\
\hline
\end{tabular}

precipitation in summer, the trend of surface pressure approximates that of $\delta^{18} \mathrm{O}$ in precipitation at the Yushu station.

In general, the variation of $\delta^{18} \mathrm{O}$ over the measurement period at the Yushu station was controlled by the temperature effect. However, the southwest monsoon transports oceanic moisture with low $\delta^{18} \mathrm{O}$ into the Yushu region in summer, especially from June to August, resulting in lower $\delta^{18} \mathrm{O}$ values than would be predicted from air temperature alone. Accordingly, the monsoon activities weaken the relationships between $\delta^{18} \mathrm{O}$ and air temperature and dew point. Before the monsoon onset and after the monsoon retreat, the periods when the westerlies dominate the moisture origins in this area, the correlations of $\delta^{18} \mathrm{O}$ with air temperature and dew point are significant.

Based on NCEP/NCAR re-analysis datasets, we calculated the wind field and humidity field at $500 \mathrm{hPa}$ for January and July in 2001 and 2002, representing winter and summer conditions, respectively. Results (January and July in 2001) are shown in Figure 5; the arrow signals indicate wind direction, and the densely shaded areas indicate humidity. This figure shows that in winter 2001 the moisture in the TP and adjacent regions was controlled by the westerlies. This results in a very strong temperature dependence of $\delta^{18} \mathrm{O}$ in precipitation at all of the stations mentioned across the TP: Yushu in the east, Tuotuohe and Nagqu in the middle, and Gaize and Shiquanhe in the west. In summer 2001, the monsoon activities transported oceanic moisture into these study regions, and heavy isotopes in oceanic moisture were more depleted along the trajectories, resulting in low $\delta^{18} \mathrm{O}$ values in precipitation and weakening the correlation between $\delta^{18} \mathrm{O}$ and air temperature. The results in 2002 are very similar to those in 2001 (figures omitted).

\section{CONCLUSIONS}

Stable isotopes in precipitation depend on many factors such as air temperature, moisture origins and precipitation processes. Here, we discuss the variation of $\delta^{18} \mathrm{O}$ with air
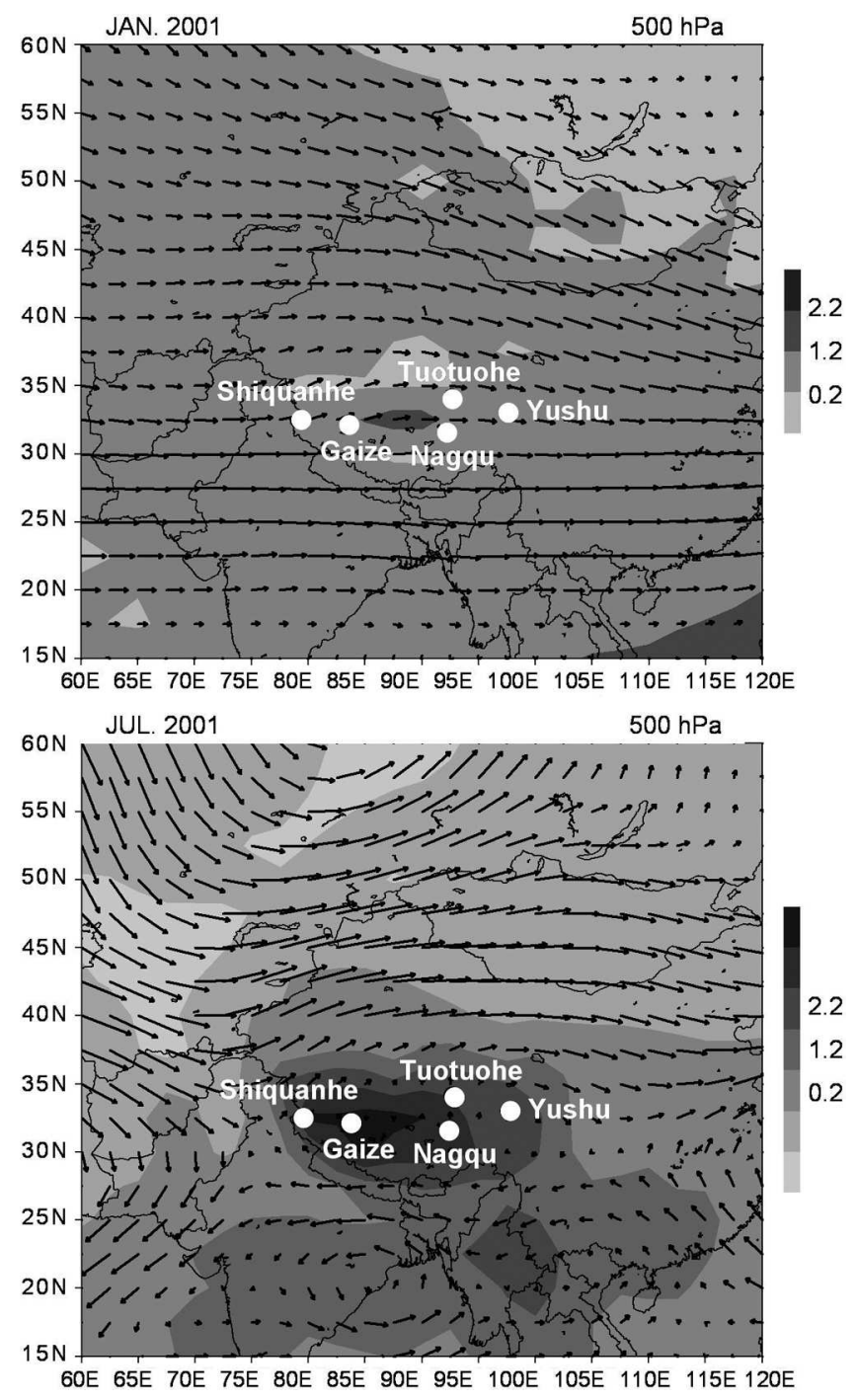

Fig. 5. Distributions of the wind field and humidity field at $500 \mathrm{hPa}$ in the winter and summer of 2001 over the TP and adjacent regions. The grayscale unit is $\mathrm{g} \mathrm{kg}^{-1}$ for humidity.

temperature, dew point and surface pressure, and discuss the effect of the southwest monsoon on the $\delta^{18} \mathrm{O}$ values in precipitation at the Yushu meteorological station.

At the Yushu station, $\delta^{18} \mathrm{O}$ in precipitation positively correlates with air temperature, especially for monthly averages. The $\delta^{18} \mathrm{O}$ values also positively correlate with dew point and surface pressure in this region. In summer, however, similar to the Nagqu, Tuotuohe, Gaize and Shiquanhe stations, all lying within a narrow band of latitude, the southwest monsoon brings high precipitation rates, which deplete the heavy isotopes, lowering $\delta^{18} \mathrm{O}$ values. Both the Yushu station and other stations are in the transition zone between the regions in the south dominated by the monsoon and the regions in the north dominated by the westerlies. Hence, before the monsoon onset and after the monsoon retreat, the correlations between $\delta^{18} \mathrm{O}$ in precipitation and air temperature and dew point are stronger than for the entire annual cycle at the Yushu station. Accordingly, the monsoon precipitation weakens the relationships between $\delta^{18} \mathrm{O}$ in precipitation and air temperature and dew point. Clearly, dew point, surface pressure and the monsoon activities all contribute to controlling the $\delta^{18} \mathrm{O}$ values in precipitation at Yushu. 


\section{ACKNOWLEDGEMENTS}

This work was supported by the Innovation Program of the Chinese Academy of Sciences (KZCX3-SW-339), the Collective Innovation of the National Natural Science Foundation of China (40121101), the Ministry of Science and Technology of the People's Republic of China (2005CB422004) and the National Natural Science Foundation of China (40571039, 40471025). We are greatly indebted to B. Currie and W. Theakstone for constructive comments during reviewing. Some meteorological data used in this paper are from the National Meteorological Information Center of China. The NCEP and NCAR provided the reanalysis datasets.

\section{REFERENCES}

Araguás-Araguás, L., K. Froelich and K. Rozanski. 1998. Stable isotope composition of precipitation over southeast Asia. J. Geophys. Res., 103(D22), 28,721-28,742.

Cuffey, K.M., R.B. Alley, P.M. Grootes, J.M. Bolzan and S. Anandakrishnan. 1994. Calibration of the $\delta^{18} \mathrm{O}$ isotopic paleothermometer for central Greenland, using borehole temperatures. J. Glaciol., 40(135), 341-349.

Dansgaard, W. 1964. Stable isotopes in precipitation. Tellus, 16(4), 436-468.

Johnsen, S.J., D. Dahl-Jensen, W. Dansgaard and N.S. Gundestrup. 1995. Greenland paleotemperatures derived from GRIP borehole temperature and ice core isotope profiles. Tellus, 47B(5), 624-629.

Johnson, K.R. and B.L. Ingram. 2004. Spatial and temporal variability in the stable isotope systematics of modern precipitation in China: implications for paleoclimate reconstructions. Earth Planet. Sci. Lett., 220(3-4), 365-377.

Jouzel, J. and L. Merlivat. 1984. Deuterium and oxygen 18 in precipitation: modeling of the isotopic effect during snow formation. J. Geophys. Res., 89(D7), 11,749-11,757.

Merlivat, L. and J. Jouzel. 1979. Global climatic interpretation of the deuterium-oxygen 18 relationship for precipitation. J. Geophys. Res., 84(C8), 5,029-5,033.
Rozanski, K., L. Araguás-Araguás and R. Gonfiantini. 1992. Relation between long-term trends of oxygen-18 isotope composition of precipitation and climate. Science, 258(5084), 981-985.

Tian, L., T. Yao and Z. Yang. 1995. Spatial distribution of $\delta^{18} \mathrm{O}$ in precipitation over the Qinghai-Tibetan, Plateau and its controlling factors. In Annual report of the study on the formation, evolution, environmental changes and ecosystem of the Qinghai-Tibetan Plateau. Beijing, Science Press, 243-250. [In Chinese.]

Tian, L., T. Yao, W. Sun, A. Numaguti and K. Toshio. 2001a. Stable isotope variation of precipitation in the middle of Qinghai Xizang Plateau and monsoon activity. Geochimica, 30(3), 217222. [In Chinese.]

Tian, L., T. Yao, A. Numaguti and W. Sun. 2001b. Stable isotope variations in monsoon precipitation on the Tibetan Plateau. J. Meteorol. Soc. Jpn, 79(5), 959-966.

Tian, L., V. Masson-Delmotte, M. Stievenard, T. Yao and J. Jouzel. 2001c. Tibetan Plateau summer monsoon northward extent revealed by measurements of water stable isotopes. J. Geophys. Res., 106(D22), 28,081-28,088.

Tian, L. and 7 others. 2003. Oxygen-18 concentrations in recent precipitation and ice cores on the Tibetan Plateau. J. Geophys. Res., 108(D9), 4293. (10.1029/2002JD002173.)

Yao, T. and 6 others. 1991. Characteristic of $\delta^{18} \mathrm{O}$ in snow and its relation with moisture sources in Tanggula Mountains, Tibetan Plateau. Chinese Sci. Bull., 36(20), 1570-1573. [In Chinese.]

Yao, T., L.G. Thompson, E. Mosley-Thompson, Z. Yang, X. Zhang and P.-N. Lin. 1996. Climatological significance of $\delta^{18} \mathrm{O}$ in north Tibetan ice cores. J. Geophys. Res., 101(D23), 29,531$29,537$.

Yao, T., V. Masson, J. Jouzel, M. Stiévenard, W. Sun and K. Jiao. 1999. Relationships between $\delta^{18} \mathrm{O}$ in precipitation and surface air temperature in the Urumqi River Basin, east Tianshan Mountains, China. Geophys. Res. Lett., 26(23), 3473-3476.

Yu, W., T. Yao, L. Tian, Y. Wang and W. Sun. 2004. Variations of $\delta^{18} \mathrm{O}$ in precipitation in the western Tibetan Plateau. J. Glaciol. Geocryol., 26(2), 146-152. [In Chinese.]

Zhang, X., Y. Shi and T. Yao. 1995. Variational features of precipitation $\delta^{18} \mathrm{O}$ in Northeast Qinghai-Tibet Plateau. Sci. China $B, \mathbf{3 8}(7)$, 854-864 